\title{
Preoperative characteristics of morbidly obese patients who achieved at least fifty percent excess weight loss post-metabolic Surgery
}

\author{
Aftab, SAS; Reddy, N; Piya, MK; Fraser, I; Menon, V; \\ Bridgwater, S; Halder, L; Kendrick, D; Kumar, S; Barber, TM \\ University Hospitals Coventry and Warwickshire, Warwick Medical School
}

\section{Background}

With the emergence of metabolic surgery as an effective and successful treatment option for obesity, the selection of obese patients who would benefit most from metabolic procedures is an on-going challenge in Bariatrics. Currently, defining patient characteristics such as health related Quality of Life (HRQOL) that would indicate suitability for metabolic surgery and would serve as outcomes of success, , is unclear. Pre-operative predictive measures of post-metabolic surgery success would facilitate a more refined evidence-based selection of patients.

\section{Objective}

This study aimed at identifying clinical and psycho-social predictors of success (defined as excess weight lost 1 year postoperatively (towards an ideal BMI $25 \mathrm{~kg} / \mathrm{m} 2$ ) [EWL-1 year]) following metabolic surgery.

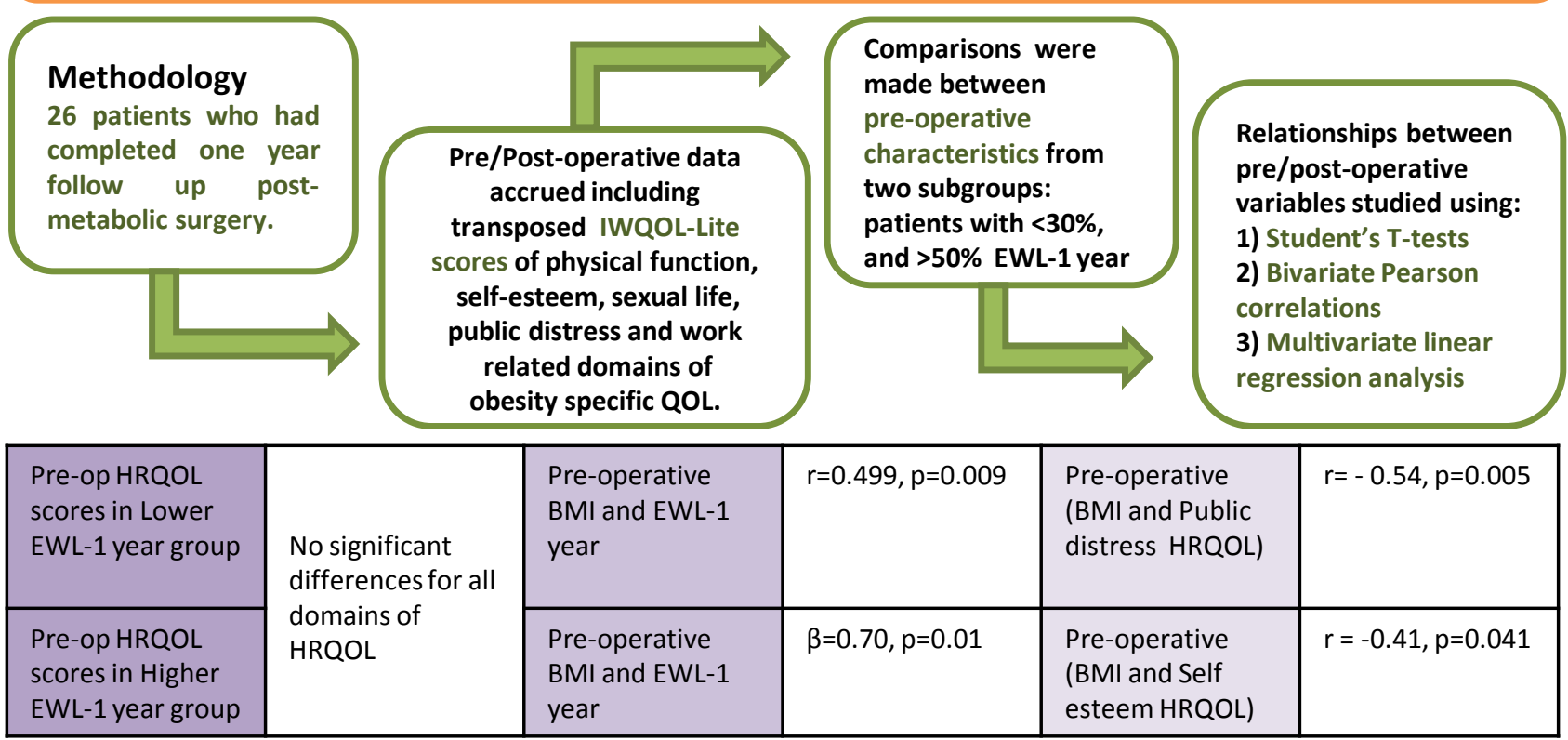

\section{Conclusions}

1) We show a significant, independent direct relation between the pre-op BMI and excess weight-loss one year following metabolic surgery,

2) Pre-operative QOL measures were not predictive of EWL-1 year.

\section{Take Home Points}

1) Excess Weight Loss 1 year post metabolic surgery is determined by variable complex factors. Pre-operative QOL may predict other measures of metabolic surgical success, such as improvements in physical and psycho-social functioning, rather than absolute weight reduction.

2) Pre-operative BMI could be considered as one of the factors that predict successful weight loss post metabolic surgery.

1) Masha Livhits, Cheryl Mercado, Irina Yermilov et al. (2012) Preoperative Predictors of Weight Loss Following Bariatric Surgery: Systematic Review. Obes Surg, 22:70-89

2) Herpertz S, Kielmann R, Wolf AM, Hebebrand J, Senf W. Do psychosocial variables predict weight loss or mental health after obesity surgery? A systematic review. Obes Res. 2004 Oct;12(10):1554-69 